\title{
Safety and Intraoperative Results in Live Kidney Donors with Vascular Multiplicity After Hand-Assisted Laparoscopy Living Donor Nephrectomy
}

\author{
Fernando Giron-Luque (iD) \\ Yenny Baez-Suarez (1D) \\ Andrea Garcia-Lopez $\mathbb{D}^{2}$ \\ Nasly Patino-Jaramillo (D) ${ }^{2}$ \\ 'Surgery Department, Colombiana de \\ Trasplantes, Bogotá, Colombia; ${ }^{2}$ Research \\ Department, Colombiana de Trasplantes, \\ Bogotá, Colombia
}

Background and Purpose: Vascular multiplicity is the most frequent anatomic variation in kidney donors. Despite concerns about risks, these allografts are increasingly used to overcome the shortage of kidney donors. The safety and clinical outcomes in living kidney donors were evaluated with vascular multiplicity after hand-assisted laparoscopic living donor nephrectomy (HALDN).

Patients and Methods: Data from all living kidney donors who underwent HALDN from 2008 to 2021 was retrospectively reviewed. Patients were divided into two groups as single (SRV) and multiple renal vessels (MRV), and a comparative analysis was done. The primary outcomes include operating room time (ORT), days of hospital stay, estimated blood loss, complications, conversion, and re-operations.

Results: MRV were present in 166 out of 612 donors (27.1\%). Among those, 10 (1.6\%) donors had simultaneous multiple arteries and veins. Additionally, the prevalence of artery and vein multiplicity was $21.8 \%(\mathrm{n}=134)$ and $3.5 \%(\mathrm{n}=22)$, respectively. Warm ischemia time was significantly different among the two groups but not clinically important. The number of conversions to open technique, the mean ORT, the median blood loss, and days of hospital stay were similar between the SRV and MRV groups, without significant differences. According to the modified Clavien-classification system, no differences were found in the complication rates between the two groups $(p=0.29)$. Complication rates were $3.3 \%$ and $3.6 \%$ for the SRV and MRV groups, respectively.

Conclusion: HALDN is a procedure with safe intraoperative results, even with vascular multiplicity. The presence of multiple renal arteries or veins has no negative impact on the outcome of the donor after living donor nephrectomy.

Keywords: kidney transplant, vascular multiplicity, living kidney donors, laparoscopic nephrectomy, anatomic variation

\section{Introduction}

Living kidney donation is crucial to increase the donor pool in renal transplantation. ${ }^{1}$ However, healthy or "ideal" living donors are not enough to accomplish a sufficient donation rate. Extended criteria for living kidney donors with obesity, hypertension, incompatibility blood group, vascular multiplicity, and older donors have been accepted in kidney transplant groups to expand opportunities for patients with chronic kidney disease on the waiting list. ${ }^{2}$
Correspondence: Andrea Garcia-Lopez Research Department, Colombiana de Trasplantes, Av Carrera 30, No. 47A-74 Bogotá, Colombia

Tel +5730050246I8

Email aegarcia@colombianadetrasplantes. com 
Simple vascular anatomy is preferred in kidneys of living donors ${ }^{3-5}$ because renal vascular multiplicity could lead to a technical difficulty in anastomosis and potential secondary complications in the donor and the recipient. Contrarily, accepting these allografts to overcome a shortage of renal donors had trended worldwide. According to the British guidelines for living donor kidney transplantation, kidneys with vascular multiplicity are not an absolute contraindication for donation, and decisions should be made on an individual clinical evaluation. ${ }^{6}$ Nevertheless, other guidelines did not make any recommendation regarding vascular multiplicity in live kidney donation. $^{2}$

Vascular multiplicity is due to the anatomical variations in the mesonephric vessels during the first trimester of fetal life. ${ }^{7-9}$ Kidneys with vascular multiplicity are common anatomical findings in kidney donors (18$30 \%){ }^{10-12}$ A review showed an overall prevalence for two renal arteries, three renal arteries, and bilateral multiple renal arteries of $25 \%, 2.6 \%$, and $10 \%$, respectively. ${ }^{13}$ The prevalence of multiple renal veins varies between $3 \%$ and $14 \%{ }^{3,13,14}$ Diverse vascular renal anomalies can be classified by their distribution of origin. ${ }^{9}$

Previous study results vary. For instance, a retrospective study with 951 live kidney donors who underwent hand-assisted laparoscopic living donor nephrectomy (HALDN) found higher warm ischemia time with no clinical impact on donors with multiple renal arteries compared to donors with a single renal artery. Additionally, no significant differences were found in complications, conversion to open surgery, calculated blood loss, length of hospital stay, re-interventions, and readmissions as compared in both groups. ${ }^{15}$ Contrarily, a publication with 1350 live kidney donors found a higher complication rate and conversion rate to open surgery in patients with vascular multiplicity than patients without vascular anomalies. ${ }^{16}$ The mortality rate in patients with vascular anomalies is similar to those without any variation. ${ }^{12}$

Most published studies described only the clinical outcomes in recipients or donors with renal vascular anomalies that report only one type of vessel variation (arterial or venous)..$^{10,17-20}$ Vascular multiplicity, including both venous and arterial anomalies, was analyzed. This study aimed to evaluate the safety and clinical outcomes in live kidney donors with single renal vessels (SRV) compared to live kidney donors with multiple renal vessels (MRV) undergoing HALDN.

\section{Materials and Methods Study Design and Study Population}

This is a retrospective observational cohort of all living kidney donors who are operated in Colombiana de Trasplantes (including a network of two centers: Bogotá and Barranquilla) from August 2008 to May 2021. During the study period, 612 consecutive kidney donors were included. No exclusions were set, and the electronic medical records of the total donors were reviewed. During this period, two surgeons performed most of the procedures (92.4\%). The feasibility of the procedure was determined after preoperative multidisciplinary donor evaluation that included appropriate psychological, medical, and surgical evaluations.

Medical evaluation of all living donors was made by a multidisciplinary team. Computed tomography angiography (CTA) was performed to identify the renal vascular anatomy and recognize renal vascular variants. The policy of our center indicates no absolute contraindication for vascular multiplicity. Kidneys with more than three arteries are not taken as no extensive literature is available on donors with more than three renal arteries and there are no definitive conclusions in this regard. Thus, the results of the safety of these donors are best applied to living donors with up to three renal arteries.

Perfusion areas of small accessory vessels were assessed before ligating and prioritizing reconstruction techniques for renal arteries or veins to not affect kidney perfusion especially if inferior polar arteries are found. Right nephrectomy was chosen in cases of confirmed lower differential renal function of the right versus the left kidney in diethylene triamine pentaacetic acid (DTPA) renogram, even with an anatomic disadvantage.

Asymmetric kidneys were defined as differences that are $>1 \mathrm{~cm}$ that affects the volume of the organ documented in CTA. In such a case, a DTPA renogram was ordered and should not show a difference of $>10 \%$ in kidney function between both kidneys to be accepted as a donor. The transplant team decided which kidney will be removed to avoid additional risk to the donor and take the kidney with less function.

Live kidney donors should have estimated the glomerular filtration rate (GFR) of $\geq 90 \mathrm{~mL} / \mathrm{min} / 1.73 \mathrm{~m}^{2}$, donors with GFR between 60 and $89 \mathrm{~mL} / \mathrm{min} / 1.73 \mathrm{~m}^{2}$ will be assessed based on age, demographics, and risk factor characteristics. $^{21}$ Live kidney donors with GFR of $<60 \mathrm{~mL} / \mathrm{min} / 1.73 \mathrm{~m}^{2}$ are not accepted for donation. 
Two groups were defined according to the number of vessels that are present in the renal pedicle. Kidneys with a single artery and vein were defined as SRV group and those with more than one artery or vein were classified as MRV group. The primary outcomes were warm ischemia time, total operating room time (ORT), days of hospital stay, blood loss, complications, conversion, and re-operations. Variables of interest were analyzed during the immediate postoperative care and after the first day when patients were discharged.

Donor complications were classified according to Kocak et al, which is a modification of the Clavienclassification system, to describe complications after live donor nephrectomy. ${ }^{22}$

\section{Operative Procedure}

The HALDN was the technique of choice. Patients were positioned in a "flank-up" position and were secured with adhesive tapes. A hand port was placed through a transverse infraumbilical or midline incision. Two trocars (5 and $12 \mathrm{~mm}$ ) and a $30^{\circ}$ video endoscope were introduced. The pneumoperitoneum level was set by infusing $\mathrm{CO}_{2}$ with a flow rate of $400 \mathrm{~cm} / \mathrm{min}$ up to a maximum of $15 \mathrm{mmHg}$ of intra-abdominal pressure. The colonic splenic flexure mobilization was conducted using the ultracision (HARMONIC ${ }^{\circledR}$ HD ultracision Johnson 1000i). Renal artery vessels and ureters were identified and dissected. Renal vessels were clamped using two large size non-absorbable polymer ligating clips (Weck ${ }^{\circledR}$ Hem-o-lok ${ }^{\circledR}$ ) and transected. ${ }^{23}$ Any secondary renal arteries were also carefully dissected until the aorta. The use of a $60 \mathrm{~mm}$ endovascular cutting stapler obtains a reasonable vessel length to mobilize and remove the right kidney. The kidney is immediately withdrawn to minimize the warm ischemia time. The kidney was delivered out through the hand port. A laparoscopic inspection was done to check for hemostasis. Urine output was maintained using intravenous hydration. Unfractionated heparin was not used before clamping the vessels. The postoperative protocol included urine catheter removal, regular diet after the first day, and analgesia on-demand.

\section{Statistical Analysis}

Descriptive and comparative analysis was carried out according to the two defined groups (SRV and MRV). Frequencies and percentages were used to describe categorical variables. Central tendency and dispersion measures were used to describe quantitative variables. Comparisons between the two groups for the main outcomes (days of hospital stay, ORT, blood loss, complications, conversion, and re-operations) were analyzed using the Chi-square and Mann-Whitney test. A $p$-value of $<0.05$ was accepted as statistically significant. Analysis was performed using the Software R version 4.0.3.

\section{Ethical Considerations}

The study was approved by the Ethics Committee Dexa Diab. This retrospective research does not present any risk according to the ethical considerations that were established in the National Regulations, such as resolution number 8430 of 1993 , published by the Ministry of Health in Colombia ${ }^{24}$ and International Regulations, such as the Declaration of Helsinki ${ }^{25}$ and the Declaration of Istanbul. ${ }^{26}$ We confirmed that all kidneys were voluntarily donated with written informed consent and that this was conducted according to the Declaration of Istanbul. ${ }^{26}$

\section{Results \\ Donor Characteristics and Clinical Outcomes}

During the study period, 612 patients had HALDN with a median age of 37.6 years, wherein 324 (52.9\%) were females and 544 (88.8\%) had left nephrectomy. The mean body mass index was $24.9 \mathrm{~m}^{2} / \mathrm{kg}$. Previous abdominal surgery was determined in $262(42.8 \%)$ patients (Table 1). The mean warm

Table I Demographic Data of Donors with and without Multiple Renal Vessels

\begin{tabular}{|l|c|c|c|c|}
\hline & All (n = 6I 2) & $\begin{array}{c}\text { Donors with } \\
\text { SRV (n= 446) }\end{array}$ & $\begin{array}{c}\text { Donors with } \\
\text { MRV (n= 166) }\end{array}$ & p-value \\
\hline Age (years) & $37.6(I I . I)$ & $37.6(11.1)$ & $37.6(11.2)$ & 0.9543 \\
Gender (\%) & $324(52.9)$ & $234(52.4)$ & $90(54.2)$ & 0.6996 \\
Female & $288(47.1)$ & $212(47.6)$ & $76(45.8)$ & 0.1080 \\
Male & $68 / 544$ & $44 / 402$ & $24 / 142$ & 0.7422 \\
Right/left kidney & $24.9(3.4)$ & $24.9(3.4)$ & $25.0(3.5)$ & 0.5970 \\
Body mass index (SD) & $262(43.4)$ & $187(42.8)$ & $75(45.2)$ & \\
Previous abdominal surgery (\%) & & & \\
\hline
\end{tabular}

Abbreviations: SRV, single renal vessels; MRV, multiple renal vessels; SD, standard deviation; IQR, interquartile range. 
Table 2 Clinical Outcomes of Donors with and without Multiple Renal Vessels

\begin{tabular}{|l|c|c|c|c|}
\hline & All (n = 6I2) & $\begin{array}{c}\text { Donors with } \\
\text { SRV (n = 446) }\end{array}$ & $\begin{array}{c}\text { Donors with } \\
\text { MRV (n = 166) }\end{array}$ & p-value \\
\hline Mean warm ischemia time, min (SD) & $3.3(2.4)$ & $3.1(1.2)$ & $3.8(4.0)$ & 0.0269 \\
Mean operative time, hour (SD) & $1.9(0.9)$ & $1.9(0.8)$ & $2.0(1.1)$ & 0.0751 \\
Median blood loss, cc (IQR) & $50(50)$ & $50(30)$ & $50(50)$ & 0.1505 \\
Number of conversion (\%) & $5(0.8)$ & $2(0.45)$ & $3(1.7)$ & 0.0968 \\
Hospital stay, days (SD) & $2.2(1.7)$ & $2.2(1.9)$ & $2.1(0.6)$ & 0.1775 \\
\hline
\end{tabular}

Abbreviations: SRV, single renal vessels; MRV, multiple renal vessels; SD, standard deviation; IQR, interquartile range.

Table 3 Comparison of Clinical Outcomes Between Single, Double and Triple Renal Arteries

\begin{tabular}{|c|c|c|c|c|}
\hline & $\begin{array}{c}\text { Single Renal } \\
\text { Artery } \\
(n=468)\end{array}$ & $\begin{array}{c}\text { Double Renal } \\
\text { Arteries } \\
(n=128)\end{array}$ & $\begin{array}{c}\text { Triple Renal } \\
\text { Arteries } \\
(n=16)\end{array}$ & p-value \\
\hline Mean warm ischemia time, min (SD) & $3.1(1.2)$ & $3.8(4.5)$ & $3.9(2.1)$ & 0.0069 \\
\hline Mean operative time, hour (SD) & $1.9(0.8)$ & $2.1(1.2)$ & $2.1(0.5)$ & 0.0962 \\
\hline Median blood loss, cc (IQR) & $50(30)$ & $50(50)$ & $67.5(50)$ & 0.0919 \\
\hline Number of conversion (\%) & $2(0.04)$ & $2(1.5)$ & I (6.25) & 0.0225 \\
\hline Hospital stay, days (SD) & $2.2(1.9)$ & $2.0(0.4)$ & $2.1(0.5)$ & 0.509 \\
\hline
\end{tabular}

Abbreviations: SRV, single renal vessels; MRV, multiple renal vessels; SD, standard deviation; IQR, interquartile range.

ischemia time was significantly different among the two groups but not clinically important. The number of conversions to open technique, the mean ORT, the median blood loss, and days of hospital stay were similar between the SRV and MRV groups, without significant differences (Table 2).

\section{Renal Artery and Vein Evaluation}

Vascular multiplicity was present in $166(27.1 \%)$ donors, of whom $10(1.6 \%)$ had simultaneous multiple arteries and veins. Additionally, the prevalence of artery and vein multiplicity was $21.8 \%(n=134)$ and $3.5 \%(n=22)$, respectively. Among the donors with simultaneous multiple renal arteries and veins, 9 (5.4\%) patients had two arteries plus two veins and one patient $(0.06 \%)$ had two arteries plus three veins (Table 2). Among the remaining 156 patients with vascular anomalies, $118(71.0 \%)$ had two arteries, $16(9.6 \%)$ had three arteries, 19 (11.4\%) had two veins, and $3(1.8 \%)$ had

Table 4 The Prevalence of Single and Multiple Renal Artery/ Arteries in 612 Living Donors

\begin{tabular}{|l|c|c|}
\hline \multirow{2}{*}{$\begin{array}{l}\text { No of Renal } \\
\text { Arteries }\end{array}$} & \multicolumn{2}{|c|}{ No. of Participants } \\
\cline { 2 - 3 } & $\begin{array}{c}\text { Right Kidney } \\
(\mathbf{n}=\mathbf{6 8 )}\end{array}$ & $\begin{array}{c}\text { Left Kidney } \\
(\mathbf{n}=\mathbf{5 4 4 )}\end{array}$ \\
\hline $\mathrm{I}$ & $5 \mathrm{I}(75.0)$ & $417(76.7)$ \\
2 & $16(23.5)$ & $112(20.6)$ \\
3 & $\mathrm{I}(0.15)$ & $15(0.28)$ \\
\hline
\end{tabular}

three veins. The comparison of clinical outcomes between single, double, and triple renal arteries revealed that warm ischemia time was significantly higher in the kidneys with triple renal arteries (Table 3).

The number of kidneys with single and multiple renal arteries and veins are described in Tables 4 and 5, respectively.

\section{Perioperative and Postoperative Complications}

No differences were found between the two groups according to the modified Clavien-classification system $(p=0.29)$ that was proposed by Kocak et $\mathrm{al}^{22}$ (Table 6). Complication rates were $3.3 \%$ and $3.6 \%$ for the SRV and MRV groups, respectively. Figure 1 shows the frequency of complications and conversions among donors. Renovascular complications were present in seven donors, including anatomical variant injuries $(n=3)$, renal artery injury $(n=1)$, renal vein injury

Table 5 The Prevalence of Single and Multiple Renal Vein/Veins in 612 Living Donors

\begin{tabular}{|l|c|c|}
\hline \multirow{2}{*}{ No of Renal Veins } & \multicolumn{2}{|c|}{ No. of Participants } \\
\cline { 2 - 3 } & $\begin{array}{c}\text { Right Kidney } \\
(\mathbf{n}=\mathbf{6 8})\end{array}$ & $\begin{array}{c}\text { Left Kidney } \\
(\mathbf{n}=\mathbf{5 4 4 )}\end{array}$ \\
\hline 1 & $57(83.8)$ & $523(96.1)$ \\
2 & $9(13.2)$ & $19(0.3)$ \\
3 & $2(0.3)$ & $2(0.04)$ \\
\hline
\end{tabular}


Table 6 Summary of Complications in Patients Undergoing Laparoscopic Donor Nephrectomy Graded by Severity

\begin{tabular}{|c|c|c|c|}
\hline Grade $^{\mathbf{a}}$ & Description & $\begin{array}{l}\text { Donors with SRV } \\
\quad(n=446)\end{array}$ & $\begin{array}{l}\text { Donors with MRV } \\
(n=166)\end{array}$ \\
\hline 1 & Epigastric vessel injury & $\mathrm{I}(0.22)$ & None \\
\hline \multirow[t]{2}{*}{$2 a$} & Anatomical variant injury & $2(0.44)$ & I (0.6) \\
\hline & Renal vein injury & I $(0.22)$ & None \\
\hline \multirow[t]{5}{*}{$2 b$} & Colon injury & $2(0.44)$ & I (0.6) \\
\hline & Duodenal injury + suture & $\mathrm{I}(0.22)$ & None \\
\hline & Renal vessels injury & None & I $(0.6)$ \\
\hline & Serosal colon injury & $2(0.44)$ & I (0.6) \\
\hline & Splenic capsule injury & $3(0.67)$ & None \\
\hline \multirow[t]{3}{*}{$2 c$} & Renal artery injury + conversion & None & $\mathrm{I}(0.6)$ \\
\hline & Splenic injury + conversion & None & I (0.6) \\
\hline & Renal vein injury + conversion & $\mathrm{I}(0.22)$ & None \\
\hline 3 & Splenectomy & $\mathrm{I}(0.22)$ & None \\
\hline \multicolumn{2}{|c|}{ Percentage of total series $(p=0.142 I)$} & $3.1 \%$ & $3.6 \%$ \\
\hline
\end{tabular}

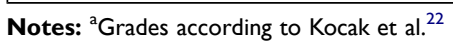

$(\mathrm{n}=1)$, and renal vessel injuries $(\mathrm{n}=1)$. Among those, four occurred in donors with SRV, and three occurred in donors with MRV. The overall conversion to open surgery rate was $0.8 \%$ ( 5 cases). One of those conversions was due to anatomical identification and dissection difficulty. Two patients had a conversion to open surgery in donors with SRV and three patients had a conversion to open surgery in donors with MRV. No deaths or re-operations were revealed among the donors (Table 6).

\section{Discussion}

As the demand for kidney transplantation continues to rise, live kidney donation becomes crucial for expanding the donor pool. The laparoscopy donor nephrectomy (LDN) has been adopted by several institutions since 1995 when Ratner et $\mathrm{al}^{27}$ reported their first experience, thus multiple advantages, such as lower hospital stay, shorter time of recovery, and better aesthetic results, ${ }^{28}$ have been documented. Our preferred operation employs a hand-assisted approach with some potential advantages over LDN, including shorter operative time, shorter learning curve, and the ability to manually assist in dissection. ${ }^{29,30}$

Potential live donors with multiple vessels are common; however, no guidelines regarding living kidney donation with renal vascular multiplicity are available, and its exclusion should be made by individual transplant centers. Renal vascular multiplicity presents a significant technical challenge as it may affect both donor safety and

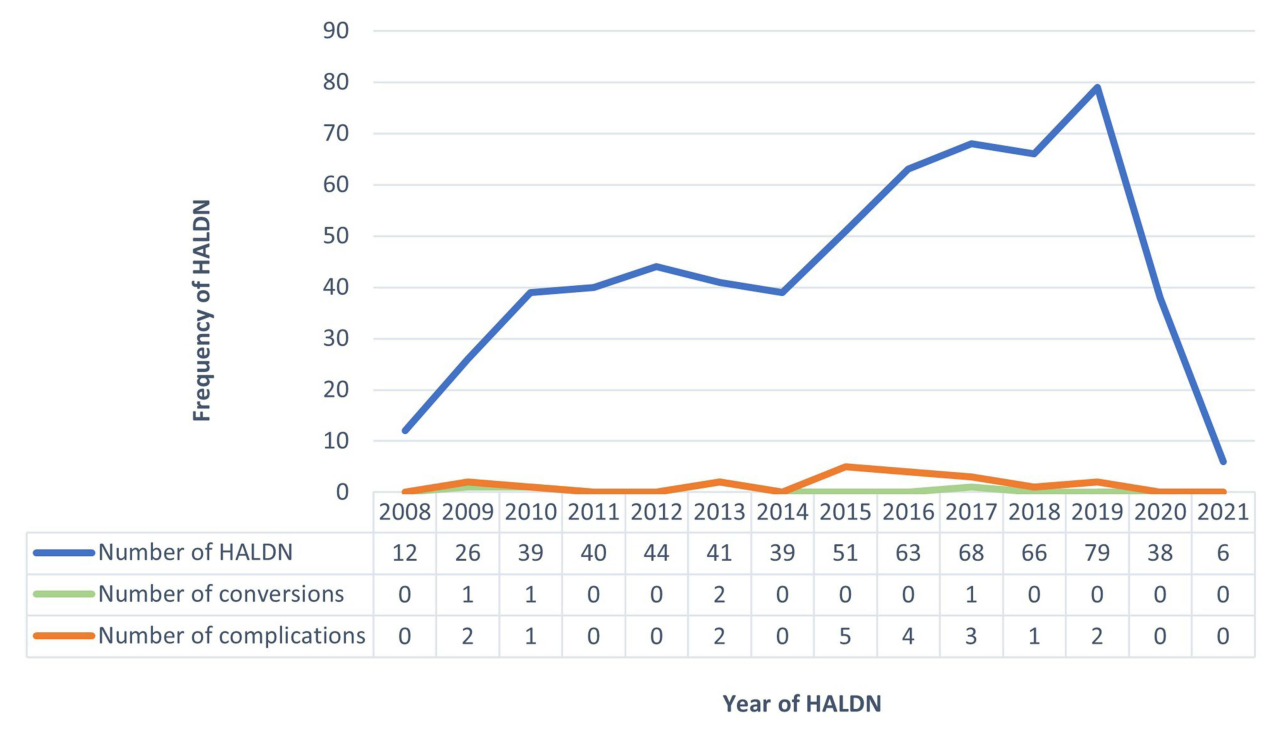

Figure I Frequency of complications and conversions among donors. 
recipient outcome. ${ }^{2}$ Most studies that report vascular multiplicity focus on recipient results, and evaluating these results in the donor seems important since it exposes an otherwise healthy patient to the risks of surgery entirely for the benefit of another person. Therefore, very little literature is found regarding donor outcomes.

This study provides an analysis and overview of data of a large cohort of live kidney donors over 12 years. This study revealed that kidneys with multiple vessels are common. Moreover, no significant differences were found in variables that would affect donor outcomes such as length of stay, operative time, the likelihood of reoperation, conversion, blood loss, and complication rate.

The incidence of supernumerary renal veins varies but is frequently seen more on the right side. ${ }^{31}$ Our study revealed $16.1 \%$ of donors on the right side and $3.8 \%$ on the left side. During nephrectomy, the vein is sacrificed when venous drainage of the smaller vein is $<20 \%$. Moreover, side-to-side anastomosis is done if two veins are of equal caliber. The incidence of accessory renal arteries fluctuates from $4 \%$ to $61.5 \%$ in a Malaysian population and Brazilian population, respectively. ${ }^{32}$ Our cohort revealed that $23.5 \%$ of kidneys have supernumerary renal arteries. Clinically, the vertical trajectory of the upper or lower polar supernumerary renal artery can lead to polar infarction and can be injured during mobilization. Therefore, the anatomical knowledge of supernumerary renal arteries is essential before performing the surgery. ${ }^{33}$

Previous studies that compared the outcomes in patients with SRV and MRV have shown variable results. A systematic review of 24 comparative studies that were published between 1970 and 2016 that was conducted by Afriansyah et $\mathrm{al}^{34}$ showed no difference in donor outcomes with multiple renal arteries compared to with single renal artery kidney.

Regarding the operative time, some centers have seen longer operating times. Troppmann et $\mathrm{al}^{35}$ reported longer operative times; however, this difference was not statistically significant. Contrarily, a higher rate of kidneys with multiple renal arteries was reported. This high rate of multiple renal artery grafts may theoretically exert an adverse effect on the outcome.

Concerning the warm ischemia time, some centers had reported higher warm ischemia time in cases with arterial multiplicity. ${ }^{35,36}$ Carter et al ${ }^{36}$ reported longer warm ischemia time in cases where multiple vessels required revascularization and could not be managed by simple ligation (pole accessory arteries of $<2 \mathrm{~mm}$ and supplying $<10 \%$ of the renal cortex).

The mean first warm ischemia time was significantly longer in donors with MRV; however, the impact on clinical outcome is minor. According to the literature, a duration of 4 min is considered to obtain renal grafts without vascular variants and between 4.5 and 5 min in kidneys with multiple arteries or veins. ${ }^{15,34}$ In comparison, some publications do not include the analysis for the donor warm ischemia time since a timeframe limit was not established, and it is not a relevant clinical factor in the donor outcomes. ${ }^{19,37}$ Our study revealed a short $(<4 \mathrm{~min})$ warm ischemia time; therefore, we hypothesized no negative impact on allograft function from a clinical perspective.

Our study revealed that live kidney donors who underwent previously abdominal surgery did not show worse outcomes than live kidney donors without abdominal surgery history. Previous abdominal surgery is not a contraindication to be a kidney live donor. ${ }^{38}$

The modified Clavien gradient system classified nephrectomy complications in the live kidney donor with SRV of grade 1 until $10 \%$, grade 2 until $2.8 \%$, grade 3 until $7 \%$, and grade 4 until $0.3 \%$. A live kidney donor with MRV has a slight classification change in proportions (grade 1 until $6 \%$, grade until $211 \%$, grade until $39 \%$, and grade 4 until $0.8 \%) .{ }^{18}$ Our classification of the perioperative complications by the modified Clavien system is similar to the results reported in the literature with HALDN and different donor nephrectomy techniques. ${ }^{22,39,40}$ Compared to our results, a retrospective study with 700 kidney live donors with HALDN calculated the modified Clavien gradient system with a higher incidence of grade 1 complications than our study, but the lower incidence in the other categories. ${ }^{19}$

Arpali et $\mathrm{a}^{16}$ revealed that the overall conversion to open surgery rate and renovascular complication rate were significantly higher in patients with multiple renal arteries. The total complication rate in our series is comparable with experiences from other centers that range between $3 \%$ and $13.5 \%{ }^{41-44}$

Our conversion rate was lower than what is reported by other authors. ${ }^{29,44}$ Our study revealed that live kidney donors with MRV and $>3$ vessels had a higher conversion rate, and cases of conversion mainly cause renovascular injuries, which is comparable with other large series. ${ }^{29}$

Finally, Hsu et $\mathrm{al}^{45}$ revealed that the use of renal allografts with multiple renal arteries does not adversely affect the parameters such as blood loss, operative time, complication rate, or hospital stay. Additionally, most 
studies showed no differences in donor outcomes with arterial multiplicity compared to living kidney donors without vascular anomalies. ${ }^{12,46-49}$

Previous studies included donors with three or fewer renal arteries. ${ }^{5,47,50,51}$ A systematic review that evaluated extended donor criterion, including vascular multiplicity, concluded that the presence of multiple renal arteries should not be a contraindication for live kidney donation. Nevertheless, as no literature was available on donors with four or more renal arteries conclusions were not made definitive in this regard. ${ }^{2}$ Additionally, our study described the presence of multiple veins, whereas the majority of studies analyzed the impact of multiple arteries. Only a few studies included donors with venous anomalies, ${ }^{3,4,15,52}$ showing that laparoscopic donor nephrectomy is safe and feasible in patients with vein anomalies. Our cohort had only ten kidneys with simultaneous multiple arteries and veins and no negative impact on donor outcomes. However, to the best of our knowledge, no study has been conducted on the clinical outcomes of donors with simultaneous multiple arteries and veins.

This study has some limitations. First, information bias intrinsic to the retrospective design is possible. Second, a low number of renal allografts with rare anatomical variations (simultaneous multiple arteries and veins) was found, and no solid conclusions may be provided about the feasibility of kidney donation in these circumstances. Moreover, the potential donors with vascular multiplicity that were excluded early in the evaluation process were not analyzed. Only intraoperative and early complications after the first day when patients were discharged were accounted and other minor complications may be possibly missed, such as wound infections, hematomas, readmission, and constipation, among others. As only early outcomes were measured, alteration of operative technique, renal function and proteinuria were not documented, and those variables are relevant to determine the safety of the procedure.

\section{Conclusion}

In conclusion, HALDN is a procedure with safe intraoperative results, even with vascular multiplicity. The presence of multiple renal veins or arteries has not significantly affected the rate of adverse intraoperative donor outcomes. Thus, renal vascular multiplicity should not be a contraindication to becoming a kidney donor. Furthermore, accepting extended criteria live kidney donors has great potential to reduce the kidney donor scarcity and improve the opportunity for transplantation and potentially reduce the mortality of those on the waiting list.

\section{Disclosure}

The authors report no conflicts of interest in this work.

\section{References}

1. Lee LY, Pham TA, Melcher ML. Living kidney donation: strategies to increase the donor pool. Surg Clin North Am. 2019;99(1):37-47. doi:10.1016/j.suc.2018.09.003

2. Ahmadi AR, Lafranca JA, Claessens LA, et al. Shifting paradigms in eligibility criteria for live kidney donation: a systematic review. Kidney Int. 2015;87(1):31-45. doi:10.1038/ki.2014.118

3. Tatarano S, Enokida H, Yamada Y, et al. Anatomical variations of the left renal vein during laparoscopic donor nephrectomy. Transplant Proc. 2019;51(5):1311-1313. doi:10.1016/j.transproceed.2019.01.132

4. Fettouh HA. Laparoscopic donor nephrectomy in the presence of vascular anomalies: evaluation of outcome. J Endourol. 2008;22 (1):77-81. doi:10.1089/end.2007.0115

5. Paragi PR, Klaassen Z, Stephen Fletcher H, et al. Vascular constraints in laparoscopic renal allograft: comparative analysis of multiple and single renal arteries in 976 laparoscopic donor nephrectomies. World J Surg. 2011;35(9):2159-2166. doi:10.1007/s00268-011-1168-6

6. British Transplantation Society. BTS/RA living donor kidney transplantation guidelines. Transplantation. 2018;4:1-295.

7. Puerta J. Embriología del aparato vascular urológico. In: Clínicas Urológicas de La Complutense. 1st ed. Universidad Complutense de Madrid; 1992:13-23.

8. Aikaterini Ntoulia FP, Benz-Bohm G. Urinary tract embryology, anatomy, and anatomical variants. In: Pediatric Urogenital Radiology. Springer International Publishing AG; 2018:852. doi:10.1007/978-3-319-39202-8

9. Arévalo Pérez J, Gragera Torres F, Marín Toribio A, Koren Fernández L, Hayoun C, Daimiel Naranjo I. Angio CT assessment of anatomical variants in renal vasculature: its importance in the living donor. Insights Imaging. 2013;4(2):199-211. doi:10.1007/ s13244-012-0217-5

10. Hostiuc S, Rusu MC, Negoi I, Dorobanțu B, Grigoriu M. Anatomical variants of renal veins: a meta-analysis of prevalence. Sci Rep. 2019;9(1):1-15. doi:10.1038/s41598-019-47280-8

11. Sarier M, Callioglu M, Yuksel Y, Duman E, Emek M, Usta SS. Evaluation of the renal arteries of 2144 living kidney donors using computed tomography angiography and comparison with intraoperative findings. Urol Int. 2020;104(7-8):637-640. doi:10.1159/000507796

12. Cho HJ, Lee JY, Kim JC, Kim SW, Hwang TK, Hong SH. How safe and effective is routine left hand-assisted laparoscopic donor nephrectomy with multiple renal arteries? A high-volume, single-center experience. Transplant Proc. 2012;44(10):2913-2917. doi:10.1016/j.transproceed.2012.04.038

13. Aldana G, Patiño G, Chadid T. Implicaciones clínicas y quirúrgicas de las variaciones anatómicas vasculares del riñón. Rev Cienc Salud. 2010;8(2):61-76.

14. Cerdan SA, Vara RG, Weitz T, Martinez GAL. Variantes anatómicas de la vena cava inferior: consideraciones prequirúrgicas. In: 31th Congreso Sociedad Española de Radiología Médica; 2012:1-36. doi:10.1594/seram2012/S-1036.

15. Lafranca JA, Van BM, Kimenai HJAN, et al. Vascular multiplicity should not be a contra-Indication for live kidney donation and transplantation. PLoS One. 2016;11(4):1-11. doi:10.1371/journal. pone. 0153460 
16. Arpalı E, Karataş C, Akyollu B, Yaprak D, Günaydın B, Koçak B. Hand-assisted laparoscopic donor nephrectomy in kidneys with multiple renal arteries versus a single renal artery: An analysis of vascular complications from 1,350 cases. Turkish J Urol. 2020;46 (4):314-319. doi:10.5152/tud.2020.19280

17. Bessede T, Droupy S, Hammoudi Y, et al. Surgical prevention and management of vascular complications of kidney transplantation. Transpl Int. 2012;25(9):994-1001. doi:10.1111/j.1432-2277.2012.01533.x

18. Tyson MD, Castle EP, Ko EY, et al. Living donor kidney transplantation with multiple renal arteries in the laparoscopic era. Urology. 2011;77(5):1116-1121. doi:10.1016/j.urology.2010.07.503

19. Nakajima I, Iwadoh K, Koyama I, Tojimbara T, Teraoka S, Fuchinoue S. Nine-yr experience of 700 hand-assisted laparoscopic donor nephrectomies in Japan. Clin Transplant. 2012;26(5):797-807. doi:10.1111/j.1399-0012.2012.01617.x

20. Harraz AM, Shokeir AA, Soliman SA, et al. Fate of accessory renal arteries in grafts with multiple renal arteries during live-donor renal allo-transplantation. Transplant Proc. 2013;45(3):1232-1236. doi:10.1016/j.transproceed.2013.02.030

21. Lentine KL, Kasiske BL, Levey AS, et al. KDIGO Clinical Practice Guideline on the Evaluation and Care of Living Kidney Donors. Transplantation. 2017;101(8S Suppl 1):S1-S109. doi:10.1097/TP.0000000000001769

22. Kocak B, Koffron AJ, Baker TB, et al. Proposed classification of complications after live donor nephrectomy. Urology. 2006;67 (5):927-931. doi:10.1016/j.urology.2005.11.023

23. Pedraza NF, Giron F, Garcia AE, Amaya JA, Baez Y. Vascular control of the renal pedicle using non-absorbable polymer ligating clips in hand-assisted living donor laparoscopic nephrectomies. Nephrourol Mon. 2019;11(3). doi:10.5812/numonthly.91761

24. Ministerio de Salud y Protección social de Colombia. Resolución número 8430 de 1993; 1993:1-19.

25. World Medical Association Declaration of Helsinki. Declaration of Helsinki; 1975.

26. The Transplantation Society. The Declaration of Istanbul; 2008.

27. Ratner LE, Ciseck LJ, Moore RG, Cigarroa FG, Kaufman HS, Kavoussi LR. Laparoscopic live donor nephrectomy. Transplantation. 1995;60(9):1047-1049.

28. Brown TS, Elster EA, Stevens K, et al. Bayesian modeling of pretransplant variables accurately predicts kidney graft survival. $\mathrm{Am}$ J Nephrol. 2012;36(6):561-569. doi:10.1159/000345552

29. Leventhal JR, Paunescu S, Baker TB, et al. A decade of minimally invasive donation: experience with more than 1200 laparoscopic donor nephrectomies at a single institution. Clin Transplant. 2010;24(2):169-174. doi:10.1111/j.1399-0012.2009.01199.x

30. Sevinç C, Özkaptan O, Balaban M, et al. Hand-assisted laparoscopic and laparoscopic donor nephrectomy: a comparison of surgical outcomes from two centres. Turkish J Urol. 2018;44(4):362-366. doi:10.5152/tud.2018.67424

31. Pandya VK, Patel AS, Sutariya HC, Gandhi SP. Evaluation of renal vascular anatomy in live renal donors: role of multi detector computed tomography. Urol Ann. 2016;8(3):270-276. doi:10.4103/09747796.184898

32. Gulas E, Wysiadecki G, Cecot T, et al. Accessory (multiple) renal arteries-Differences in frequency according to population, visualizing techniques and stage of morphological development. Vascular. 2016;24(5):531-537. doi:10.1177/1708538116631223

33. Budhiraja V, Rastogi R, Anjankar V, Babu CSR, Goel P. Supernumerary renal arteries and their embryological and clinical correlation: a cadaveric study from north India. ISRN Anat. 2013;2013:405712. doi:10.5402/2013/405712

34. Afriansyah A, Rasyid N, Rodjani A, et al. Laparoscopic procurement of single versus multiple artery kidney allografts: meta-analysis of comparative studies. Asian J Surg. 2019;42(1):61-70. doi:10.1016/j. asjsur.2018.06.001
35. Troppmann C, Wiesmann K, McVicar JP, Wolfe BM, Perez RV. Increased transplantation of kidneys with multiple renal arteries in the laparoscopic live donor nephrectomy era: surgical technique and surgical and nonsurgical donor and recipient outcomes. Arch Surg. 2001;136(8):897-907. doi:10.1001/archsurg.136. 8.897

36. Carter JT, Freise CE, McTaggart RA, et al. Laparoscopic procurement of kidneys with multiple renal arteries is associated with increased ureteral complications in the recipient. Am J Transplant. 2005;5(6):1312-1318. doi:10.1111/j.1600-6143.2005.00859.x

37. Paramesh A, Zhang R, Florman S, et al. Laparoscopic procurement of single versus multiple artery kidney allografts: is long-term graft survival affected? Transplantation. 2009;88(10):1203-1207. doi:10.1097/TP.0b013e3181ba343a

38. Kidney Disease: Improving Global Outcomes (KDIGO) Living Kidney DonorWork Group. KDIGO clinical practice guideline on the evaluation and care of living kidney donors. Transplantation. 2017;101(Supp18S):S1-S109.

39. Srivastava A, Bansal A, Sureka S, et al. A retrospective analysis of complications of laparoscopic left donor nephrectomy using the Kocak's modification of Clavien-Dindo system. Indian $J$ Urol. 2018;34(2):133-139. doi:10.4103/iju.IJU_111_17

40. Garcia-Ochoa C, Feldman LS, Nguan C, et al. Perioperative complications during living donor nephrectomy: results from a multicenter cohort study. Can J Kidney Health Dis. 2019;6. doi:10.1177/ 2054358119857718

41. Raber B, Westmoreland M, Arnold D, et al. Laparoscopic donor nephrectomy: a single institution minimally invasive general surgeon experience 1999-2013. Am J Surg. 2017;214(6):1220-1225. doi:10.1016/j.amjsurg.2017.08.038

42. Cintorino D, Pagano D, Bonsignore P, et al. Evolution of technique in laparoscopic donor nephrectomy: a single center experience. J Laparoendosc Adv Surg Tech. 2017;27(7):666-668. doi:10.1089/ lap.2017.0140

43. Felix B, Uyen H, Karine H, et al. Early complications after living donor nephrectomy: analysis of the Swiss organ living donor health registry. Swiss Med Wkly. 2017;147(3334):1-7. doi:10.4414/smw.2017.14497

44. Leventhal JR, Kocak B, Salvalaggio PRO, et al. Laparoscopic donor nephrectomy 1997 to 2003: lessons learned with 500 cases at a single institution. Surgery. 2004;136(4):881-890. doi:10.1016/j.surg.200 4.06 .025

45. Hsu THS, Su LM, Ratner LE, Trock BJ, Kavoussi LR. Impact of renal artery multiplicity on outcomes of renal donors and recipients in laparoscopic donor nephrectomy. Urology. 2003;61(2):323-327. doi:10.1016/S0090-4295(02)02124-6

46. Desai MR, Ganpule AP, Gupta R, Thimmegowda M. Outcome of renal transplantation with multiple versus single renal arteries after laparoscopic live donor nephrectomy: a comparative study. Urology. 2007;69(5):824-827. doi:10.1016/j.urology.2007.01.026

47. Hung CJ, Lin YJ, Chang SS, Chou TC, Lee PC. Kidney grafts with multiple renal arteries is no longer a relative contraindication with advance in surgical techniques of laparoscopic donor nephrectomy. Transplant Proc. 2012;44(1):36-38. doi:10.1016/j.transproceed.2011.12.027

48. Meyer F, Nichele SA, Adamy A, Santos LS, Machado C. Early outcomes of laparoscopic donor nephrectomy with multiple renal arteries. Int Braz J Urol. 2012;38(4):496-502. doi:10.1590/S167755382012000400009

49. Wijayaratne DR, Sudusinghe DH, Gunawansa N. Multiple renal arteries in live donor renal transplantation; impact on graft function and outcome: a prospective cohort study. Open J Organ Transpl Surg. 2018;08(01):1-11. doi:10.4236/ojots.2018.81001

50. Kapoor A, Lambe S, Kling AL, Piercey KR, Whelan PJ. Outcomes of laparoscopic donor nephrectomy in the presence of multiple renal arteries. Urol Ann. 2011;3(2):62-65. doi:10.4103/09747796.82169 
51. Bagul A, Frost JH, Mathuram Thiyagarajan U, Mohamed IH, Nicholson ML. Extending anatomic barriers to right laparoscopic live donor nephrectomy. Urology. 2012;79(2):465-469. doi:10.1016/ j.urology.2011.10.008
52. Patil AB, Javali TD, Nagaraj HK, Babu SMLP, Nayak A. Laparoscopic donor nephrectomy in unusual venous anatomy donor and recepient implications. Int Braz J Urol. 2017;43 (4):671-678. doi:10.1590/S1677-5538.IBJU.2016.0309

\section{Publish your work in this journal}

Research and Reports in Urology is an international, peer-reviewed, open access journal publishing original research, reports, editorials, reviews and commentaries on all aspects of adult and pediatric urology in the clinic and laboratory including the following topics: Pathology, pathophysiology of urological disease; Investigation and treatment of urological disease; Pharmacology of drugs used for the treatment of urological disease. The manuscript management system is completely online and includes a very quick and fair peer-review system, which is all easy to use. Visit http://www.dovepress.com/ testimonials.php to read real quotes from published authors. 